PREPRINT. This paper is a pre-print of the article published in the American Journal of Community Psychology, in the original format, before peer review and the subsequent editorial process. To cite this document, please use the following reference:

Maya-Jariego, I. (2018). Why name generators with a fixed number of alters may be a pragmatic option for personal network analysis. American Journal of Community Psychology, 62 (1-2), 233-238. DOI 10.1002/ajcp.12271

\title{
COMMENTARY
}

\section{Why name generators with a fixed number of alters may be a pragmatic option for personal network analysis}

Isidro Maya Jariego

Universidad de Sevilla

Abstract. Social network analysis (SNA) has grown exponentially in recent years, giving rise to methodological innovations in different scientific disciplines. In psychology, SNA has been incorporated into studies of individual personality differences and has generated novel areas, such as network psychometrics and network interventions. In community psychology, a recent review examined the use of network analysis in American Journal of Community Psychology publications (Neal \& Neal, 2017). Based on their study, the authors advise researchers to avoid using the fixed-choice name generator when possible, as one of the five methodological recommendations proposed. In this essay, I explain how the recent increase of name generators with a fixed number of alters when studying personal networks is originally linked to an interest in describing structural properties. Second, I analyze the pragmatic contributions of this method: establishing a limit of alters a priori can entail advantages in terms of standardization and comparability of personal networks. Finally, to contextualize the methodological debate, I argue that personal networks represent the diversity of contexts in which the individual participates and are naturally integrated into community surveys.

Keywords: Personal networks, egocentric networks, structure of social networks, name generators.

\section{Network analysis in psychology}

Social network analysis (SNA) has grown exponentially in the last twenty years, with a significant inflection point at the end of the 1990s (Borgatti \& Foster, 2003; Borgatti \& Halgin, 2011; Borgatti, Mehra, Brass \& Labianca, 2009; Jackson, 2015; McCarty \& Molina, 2014). This has led to new developments in different disciplines and fields of research, which have resulted in methodological innovations. Consequently, the rise of network research is linked to an increase in the diversity of its applications.

In the last two decades, network analysis has developed in a similar fashion in the field of psychology. On the one hand, this has consisted in recovering the study of structural properties of groups (Wölfer, Faber \& Hewstone, 2015), which in part is restoring the traditions of field theory and sociometry (Freeman, 2004; Scott, 2017). On the other hand, there have also been 
new developments in the confluence of networks with psychology: among others, it is worth highlighting (1) the study of the influence of individual personality differences in social networks (Kalish \& Robins, 2006), (2) psychometric applications in the study of mental disorders (Borsboom, 2008), and (3) network-based interventions (Valente, 2012). These are summarized in Table 1.

In the first of these three lines of research, the model of the Big Five personality factors has been used to explore the individual differences in the patterns of sociability, in the structural properties of personal networks and in the position of individuals in the socio-centric networks (Roberts, Wilson, Fedurek \& Dunbar, 2008, Selden \& Goodie, 2018). In contrast to the structuralist approach, this means recognizing that the agency of the actors of a network can influence its topology (Krause, James \& Croft, 2010), resulting in a novel examination of individual interactive strategies in social networks.

Secondly, the notion of mental illness as a network of symptoms that interact with each other has served to explain the co-morbidities of disorders that usually appear together with certain frequency (Cramer, Waldorp, van der Maas \& Borsboom, 2010). Network psychometrics have shown that individuals who suffer from a psychopathology have a different symptom structure than healthy people, and that intervention in those symptoms with greater centrality can be especially effective in psychological treatments (Epskamp, Maris, Waldorp \& Borsboom, 2016; Epskamp, Rhemtulla \& Borsboom, 2017; Fried et al., 2017).

Third, relational data has been used in the design, implementation and evaluation of interventions to promote behavioral change. Mainly, the analysis of social structures allows selecting agents of change and segmenting in natural groups in an efficient manner (Valente, 2012). In practice, social networks have been integrated with strategies to identify opinion leaders, to monitor community coalitions and to improve the implementation of programs (Maya-Jariego \& Holgado, 2015). In some cases, the interventions are based on underlying dynamics of social interaction to improve effectiveness, while in other cases the analysis and visualization of the networks are an intervention tool in themselves (Maya-Jariego, 2016).

Table 1

Psychological applications of social network analysis

\begin{tabular}{|c|c|c|}
\hline Theme & Applications & Innovations \\
\hline $\begin{array}{l}\text { Individual personality } \\
\text { differences }\end{array}$ & $\begin{array}{l}\text { Networks variability } \\
\text { according to the Big Five } \\
\text { traits }\end{array}$ & $\begin{array}{l}\text { - Introduction of the individual } \\
\text { agency in network analysis. } \\
\text { - } \quad \text { Mixed methodological } \\
\text { strategies. }\end{array}$ \\
\hline $\begin{array}{l}\text { Psychological evaluation } \\
\text { of symptoms }\end{array}$ & Network psychometrics & $\begin{array}{l}\text { Diagnosis of the structure of } \\
\text { symptoms and comorbidity. } \\
\text { - Identification of central } \\
\text { symptoms for psychological } \\
\text { treatment. }\end{array}$ \\
\hline Action-research & $\begin{array}{l}\text { Design, implementation and } \\
\text { evaluation of network-based } \\
\text { interventions }\end{array}$ & $\begin{array}{l}\text { - Consideration of social } \\
\text { structures for interventions. } \\
\text { - Analysis and visualization of } \\
\text { networks as an intervention } \\
\text { tool. }\end{array}$ \\
\hline
\end{tabular}




\section{Social network analysis and community intervention}

Consistent with these trends, network analysis has developed in the field of social and community interventions (Maya-Jariego \& Holgado, 2015). To reaffirm its potential in this field, it has been proposed as a methodological strategy that "captures the context" (Luke, 2005), and that allows a simultaneous analysis of the micro and macro-social levels (Maya-Jariego, 2004). It is also used to reinterpret in relational terms some of the central concepts in community psychology. For example, indicators of structural cohesion, which tend to be associated with the psychological sense of community, could be used as an empirical proxy of community membership and integration (Maya-Jariego, 2004). Likewise, social networks are very effective in the operationalization of ecological concepts, such as social regularities (Quiroz Saavedra, Brunson \& Bigras, 2017) and behavioral settings (Maya-Jariego, Holgado, Márquez \& Santolaya, 2018).

In this context, Zachary P. Neal and Jennifer Watling Neal conducted a systematic analysis of the use of network analysis in the articles published in the American Journal of Community Psychology (AJCP). According to this review, "because network analysis focuses explicitly on patterns of relationships between actors, their theories and methods are inherently extraindividual in nature and particularly well suited to characterizing social contexts" (Neal \& Neal, 2017, p 279). Since its foundation in 1974, the AJCP has published research with both personal network data $(n=17)$ and complete network data $(n=29)^{1}$. Personal networks evaluate the impact of the social environment on the individual, while complete networks focus on understanding processes in community contexts and allow explanations that range from the micro level to the macro-social level. For this, both types of studies, personal networks and complete networks, have been based mainly on the indicators of centrality (preferably degree) and density. In the case of sociocentric networks, the identification of subgroups in the network is also sometimes used.

Based on this previous analysis, Neal and Neal (2017) propose five recommendations to improve the applications of network analysis in the field of community psychology in the near future, namely: (1) avoid fixed-choice designs in the name generators, (2) implement motivation and incentive strategies that minimize missing data, (3) explain explicitly the network metric used as an operationalization of the theoretical concepts analyzed, (4) verify that the assumptions of independence for the application of parametric tests are met and, finally, (5) reflect in each case on the biases related to the way in which the data have been collected, treated and analyzed.

These five recommendations are based on limitations and difficulties found in previous research. In addition, they are presented in a way that can help researchers in making methodological decisions and in research design implementation. In my opinion, this list of suggestions identifies some of the main challenges of relational data management in community research and action. However, the first recommendation is partially in contradiction with an emerging practice in the last two decades of analysis of personal networks, consisting of establishing a fixed number of

\footnotetext{
${ }^{1}$ It is important to add the distinction between data of relationships referred to Ego that are extracted from already existing whole networks and "personal networks", which refer instead to links that are not limited to a specific whole network, and that are typically obtained in surveys of samples of individuals. Personal networks analysis, our focus in this commentary, usually refers to sets of social relationships that are distributed in all the social settings in which ego participates, such as the neighborhood, the workplace, and others (Hâncean, Molina \& Lubbers, 2016). In fact, the possibility of capturing the diversity of social contexts in which the individual is integrated is one of the characteristics that makes it attractive for community psychology.
} 
alters to evaluate each respondent's surrounding social structure. As Neal and Neal rightly indicate, these types of name generators entail analytic limitations in the calculation of network indicators, which leads them to conclude that "whether collecting data using a roster or free recall, respondents should be permitted to name as many actors as they wish" (p. 288). However, there are practical considerations that may warrant the use of designs with a fixed number of alters in certain circumstances. Hence, we cannot simply generalize the restrictions attributed to fixed-choice name generators, to the name generators with a fixed number of alters. This assertion is what I develop further in the following section.

\section{Standardization and comparison of the structural properties of personal networks}

The main limitation attributed to fixed-choice designs is measurement error. Specifically, requesting a fixed number of alters can introduce systematic biases in the distribution of missing data, conditions the underlying structure of grouping into differentiated subsets, and affects the calculation of structural properties (Holland \& Leinhardt, 1973; Kossinets, 2006; Neal \& Neal, 2017). The typical result is an inadequate representation of the characteristics of the networks. This consequence is perfectly illustrated in the article by Neal and Neal (2017) (see especially the comment referred to Fig. 3, pp. 287-288).

One of the most active lines of research has been the estimation of the size of personal networks, together with the exploration of individual variability in this regard (Bernard et al., 1990; Killworth, Bernard \& McCarty, 1984, Killworth, Johnsen, Bernard, Shelley \& McCarty, 1990, McCarty, Killworth, Bernard, Johnsen \& Shelley, 2000, Molina, 2005). Through different evaluation strategies, it has been suggested that generally people have between 1 and 3 confidants, between 10 and 20 support providers, and between 150 and 300 stable active relationships; which can reach up to 3000 acquaintances (Dunbar, 1992, Killworth et al., 1990, Maya-Jariego, 2006, Molina, 2005). Taking into account the central role that the size of the personal network has had, both in substantive studies and in the examination of the accuracy of the informants, why then propose a strategy that dispenses with this dimension in the study of personal networks?

The recent extension of the use of name generators with a fixed number of alters in the study of personal networks is linked to an interest in analyzing structural properties, beyond the mere estimation of the size of the networks (McCarty, 2002 ). In a seminal article published in 2002, Christopher McCarty proposed (1) applying the same type of structural analysis that was traditionally used with socio-centric networks to personal network data; and (2) obtaining a broad list of alters, requesting each interviewee to list a prefixed number of names of members of their network ${ }^{2}$. Until then most of the studies on personal networks were based exclusively on attributive data and focused on the core of the network, limited to less than 10 members.

For example, the literature of social support, with a broad development in psychology since the 1970 s, has focused on describing the characteristics and functions of support providers, without

\footnotetext{
${ }^{2}$ Consequently, in this case, it is not exactly a fixed-choice name generator but a free-recall name generator with a fixed number of alters. In fact, it may be convenient to review the terminology we use to refer to the different name generators. A tool is considered "fixed-choice" when the respondent has to choose a fixed number (or a maximum) of alters from a list; while "free-recall" refers to the free listing of alters without any previous suggestion (Wasserman \& Faust, 1994). In doing so, two dimensions are really being combined in the classification: the name generators can be based on a roster or free-recall, with a limit of names or without limitations. The name generator proposed by McCarty is hitherto an unusual combination, consisting of relying on the "free-recall" of the respondents, but with a fixed limitation on the number of alters to be mentioned.
} 
examining their relationship to each other (Maya-Jariego, 2006). If anything, analysis was based on the subset of stronger ties, people with whom a more frequent and more intense relationship is maintained. That is, no matrix data have been generated that could be subjected to network analysis (which has been the most frequent); or data has been obtained on a small subset of relationships, usually densely connected to each other. In this second case, although network measures are obtained, they do not usually capture the diversity of personal network structures. This is what led Christopher McCarty to suggest that generating a relatively broad list of names helps to represent the variability of structural properties.

The preference for attributive data and the limitation to a small number of members of the network does not seem to depend exclusively on the theoretical assumptions of the research. It is also related to the significant workload usually involved in the collection, processing and analysis of this type of data. In practice, it is very expensive in time and effort. On the one hand, completing the actor by actor matrix generates overload and fatigue in the informants. On the other hand, standardization and analysis of data is multiplied by the number of matrices of personal networks, which generally coincides with the number of respondents. Concern with the network size has partially been replaced by the question about the minimum number of alters that must be obtained to get an adequate representation of the structure of the network (Molina, 2005). That is, it is intended to reduce as much as possible the number of alters to avoid overload, but at the same time it aims to acquire the minimum from each respondent that allows to capture the structural properties of his/her personal network. Since the original proposal of using a minimum of 60 alters (McCarty, 2002), in different investigations, the numbers oscillated between 40 and 60 alters, and it has been estimated that approximately 30 may be sufficient to capture the distinctive structural properties of each personal network.

Another indirect effect of establishing a fixed number of alters is the standardization of network measures without the need for additional data processing. For example, the direct calculation of the density of two different personal networks is comparable in the extent to which they have the same number of nodes and, therefore, with the same number of potential ties. That is, it has the same effect as statistical normalization. It also greatly reduces the time required for data treatment and processing, especially when a computer program is combined to calculate network indicators (e.g., UCINET) with another to perform inter-individual statistical analysis (e.g., SPSS) ${ }^{3}$; or when alternative meta-analysis strategies are used.

In fact, homogenization can be seen from the data collection phase, by imposing the same conditions of application to all participants. When this procedure is followed, it is normal for respondents to primarily list intimate ties and then complete the list progressively with weaker ties. Moreover, while some individuals can easily complete the name generator others may face difficulties completing the required number. It is very probable that these individual differences correspond to variations in the size of the personal network and are indirectly reflected in the relative prevalence of weak ties and in the structural properties of each network.

In Table 2, I have summarized the advantages that can be obtained with this type of name generators. As I have explained, the use of name generators with a fixed number of alters arises from an interest in analyzing the structural characteristics, through a procedure that allows the comparison in surveys of personal networks, reducing as much as possible the processing load.

\footnotetext{
${ }^{3}$ First, the network measures of each personal network are calculated (with a software for network analysis); and then they are incorporated into a database as attributive variables of each respondent (that is, with a statistical package).
} 
This strategy has worked effectively in practice, allowing for standardization and comparability, with a more feasible processing load. Hence, this is why it may be one of the tools useful for certain research purposes.

In Figure $1 \mathrm{I}$ illustrate how the use of a fixed number of alters facilitates the comparison and interpretation of the structural properties of personal networks, reducing the time spent in data processing (for example, with standardization procedures that require calculations with each of the individual matrices). By imposing homogeneous criteria for observing and collecting information, we obtain comparable data. Moreover, it facilitates the detection of patterns and the interpretation of data. For instance, the three personal networks represented in Figure 1 vary in density, in modularity and in their level of fragmentation, although they all have the same size. This allows us to detect "types" of personal networks from the point of view of their structure, which make a worthwhile contribution in community surveys. In the case of having a different size, we would first have to rule out that the diversity of structures does not depend on such variable.

Table 2

Practical advantages of collecting a fixed number of alters in personal network surveys

\begin{tabular}{|c|c|c|}
\hline Needs & Description & Advantages \\
\hline $\begin{array}{l}\text { Structural } \\
\text { analysis }\end{array}$ & $\begin{array}{l}\text { - Change the focus from network size } \\
\text { estimation to the analysis of structural } \\
\text { properties, with alter-alter matrices. } \\
\text { - Extend the observation beyond densely } \\
\text { connected core of the network. }\end{array}$ & $\begin{array}{ll}\text { - Obtaining network } \\
\text { indicators } \\
\text { - } \\
\text { Representing } \\
\text { structure variability }\end{array}$ \\
\hline $\begin{array}{l}\text { Compare } \\
\text { personal } \\
\text { networks }\end{array}$ & $\begin{array}{l}\text { Establish homogeneous conditions for } \\
\text { obtaining information about alter-alter } \\
\text { relationships. } \\
\text { - Force a listing of ties with different levels } \\
\text { of importance. }\end{array}$ & $\begin{array}{l}\text { - Standardization } \\
\text { - } \quad \text { Comparability }\end{array}$ \\
\hline $\begin{array}{l}\text { Reduce the } \\
\text { processing load }\end{array}$ & $\begin{array}{l}\text { - Implement a direct strategy for data } \\
\text { normalization. } \\
\text { - } \quad \text { Reduce the time spent on data processing. } \\
\text { Estimate the minimum number of names } \\
\text { necessary to capture the diversity of } \\
\text { structures. }\end{array}$ & $\begin{array}{l}\text { - Standardization } \\
\text { - Comparability }\end{array}$ \\
\hline
\end{tabular}

--HERE FIGURE 1--

\section{Conclusions}

In this commentary, I have explored the practical advantages of using a name generator with a fixed number of alters in the analysis of personal networks. While size estimation through unlimited choice designs are important for research, name generators with a fixed number of alters may also be useful. As it has been argued in this commentary, establishing an a priori limit of alters can facilitate standardization and comparability in personal network surveys, a procedure that has been productive in recent years. This approach has identified some of the basic factors in structural variability (such as cohesion, integration and fragmentation) (Lozares, Martí, Molina \& García-Macías, 2013; Maya-Jariego \& Holgado, 2015b); and it could serve to 
elaborate typologies according to the density and modularity of personal networks (Bidart, Degenne \& Grossetti, 2018, Giannella \& Fischer, 2016, Maya-Jariego, 2002, Maya-Jariego, Letina \& González-Tinoco, 2018 ).

Although setting a limit on the number of people that can be mentioned, as explained by Neal and Neal (2017), introduces biases in the calculation of network measures, as yet in psychology a reasonable margin of error is often assumed. Even if not basing our determinations on the calculation of probabilities, graph theory is also vulnerable to biases during the collection and processing of information. It may be argued that boundary specification in sociocentric networks could have similar effects to a fixed-choice design: Any "complete" network is part of a larger social structure, so taking into account these other ties would affect the structural properties of the observed network ${ }^{4}$.

My conclusion is that, under certain conditions, we can assume a margin of error if there are other practical considerations that justify the use of a particular tool. In any case, it depends on each specific case of investigation. Research design always involves trade-offs. That is why it is important to take into consideration some of the advantages that a fixed number of alters in the name generators can have under certain circumstances or for certain goals.

Adopting a pragmatic approach, the methodology applied fits with aims of community studies. Thus, obtaining a minimum number of alters is not only a methodological issue, but a necessary requirement to represent the diversity of contexts in which the individual participates. It is a tool with enormous potential for community research: network analysis moves beyond an individual perspective, allows the evaluation of the interdependence between actors in a setting and is especially suitable to measure contextual processes (Kornbluh \& Neal, 2015). Therefore, this structural approach is effective in studying the individuals' exchanges with their environment, as well as representing social system dynamics (Jason et al., 2015), typical of community psychology. In addition, the understanding of community networks may also be useful to guide social action (Jason, Light \& Callahan, 2015).

The study of personal networks, with a structural approach, has enormous potential in the psychology of social and community intervention. First, it allows the integration of relational data in community surveys, which may enable generalizing to the entire population. Second, it enables a comprehensive description of the multiple contexts in which an individual participates 5 . Third, it provides strategies with which to examine "meso" structures, exploring the interaction between individuals, institutions and social structures (Ferrand, 2002). Each of these developments will allow us to explore new avenues, albeit with some flexibility, in the collection and analysis of data. After all, these applications of structural analysis have only just begun.

\footnotetext{
${ }^{4}$ Although each member of the network is free to indicate a different number of alters, also in that case we are establishing an implicit limit in the generation of names: individuals included in an organization, setting or a priori category.

${ }^{5}$ Unlike sociocentric networks, which usually examine the structure of a single interaction context.
} 


\section{References}

Bernard, R. H., Johnsen, E. C., Killworth, P. D., McCarty, C., Shelley, G. A \& Robinson, S. (1990). Comparing four different methods for measuring personal social networks. Social Networks 12, 179-215.

Bidart, C., Degenne, A., \& Grossetti, M. (2018). Personal networks typologies: A structural approach. Social Networks, 54, 1-11.

Borgatti, S. P., \& Foster, P. C. (2003). The network paradigm in organizational research: A review and typology. Journal of management, 29(6), 991-1013.

Borgatti, S. P., \& Halgin, D. S. (2011). On network theory. Organization science, 22(5), 1168-1181.

Borgatti, S. P., Mehra, A. \& Brass, D. J., Labianca G. (2009). Network Analysis in the Social Sciences. Science, 323(5916), 892-895.

Borsboom, D. (2008). Psychometric perspectives on diagnostic systems. Journal of clinical psychology, 64(9), 1089-1108.

Cramer, A. O. J., Waldorp, L. J., van der Maas, H. L. J. \& Borsboom, D. (2010). Comorbidity: a network perspective. Behavioral and Brain Sciences, 33(2-3), 137-150. $\underline{10.1017 / S 0140525 \times 09991567}$

Dunbar, R. I. (1992). Neocortex size as a constraint on group size in primates. Journal of Human Evolution, 22(6), 469-493.

Epskamp, S., Maris, G. K., Waldorp, L. J., \& Borsboom, D. (2016). Network psychometrics. arXiv preprint arXiv:1609.02818.

Epskamp, S., Rhemtulla, M., \& Borsboom, D. (2017). Generalized Network Pschometrics: Combining Network and Latent Variable Models. Psychometrika, 82(4), 904-927.

Ferrand, A. (2002). Las comunidades locales como estructuras meso. REDES. Revista Hispana para el Análisis de Redes Sociales, (3), \#4. Disponible en: http://revista-redes.rediris.es

Freeman, L. (2004). The development of social network analysis. A Study in the Sociology of Science. Empirical Press: Vancouver, Canada.

Fried, E. I., van Borkulo, C. D., Cramer, A. O., Boschloo, L., Schoevers, R. A., \& Borsboom, D. (2017). Mental disorders as networks of problems: a review of recent insights. Social Psychiatry and Psychiatric Epidemiology, 52(1), 1-10.

Giannella, E., \& Fischer, C. S. (2016). An inductive typology of egocentric networks. Social Networks, 47, 15-23.

Hâncean, M. G., Molina, J. L., \& Lubbers, M. J. (2016). Recent advancements, developments and applications of personal network analysis. International Review of Social Research, 6(4), 137145.

Holland, P.W., \& Leinhardt, S. (1973). The structural implications of measurement error in sociometry. Journal of Mathematical Sociology, 3, 85-111.

Jackson, M. (2015). The past and future of network analysis in economics. In Y. Bramoullé, A. Galeotti \& B. Rogers (Eds.). The Oxford Handbook of the Economics of Networks. DOI: 10.1093/oxfordhb/9780199948277.013.2 
Jason, L. A., Light, J. \& Callahan, S. (2015). Dynamic Social Networks. In Leonard A. Jason, David S. Glenwick (Eds.), Handbook of Methodological Approaches to Community-Based Research, 207-218. New York: Oxford University Press.

Kalish, Y., \& Robins, G. (2006). Psychological predispositions and network structure: The relationship between individual predispositions, structural holes and network closure. Social networks, 28(1), 56-84.

Killworth, P. D., Bernard, H. R. \& McCarty, C. (1984). Measuring Patterns of Acquaintanceship. Current Anthropology, 23, 318-397.

Killworth, P. D., Johnsen, E. C., Bernard, H. R., Shelley, G. A. \& McCarty, C. (1990). Estimating the size of personal networks. Social Networks, 12, 289-312.

Kornbluh, M. \& Neal, J. W. (2015). Social Network Analysis. In Leonard A. Jason, David S. Glenwick (Eds.), Handbook of Methodological Approaches to Community-Based Research, 219229. New York: Oxford University Press.

Kossinets, G. (2006). Effects of missing data in social networks. Social Networks, 28, 247-268.

Krause, J., James, R., \& Croft, D. P. (2010). Personality in the context of social networks. Philosophical Transactions of the Royal Society B: Biological Sciences, 365(1560), 4099-4106.

Lozares, C., Martí, J., Molina, J. L., \& García-Macías, A. (2013). La cohesión-integración versus la fragmentación social desde un perspectiva relacional. Metodología de Encuestas, 15, 57-75.

Luke, D. A. (2005). Getting the big picture in community science: Methods that capture context. American Journal of Community Psychology, 35(3-4), 185-200.

Maya Jariego, I. (2002). Tipos de redes personales de los inmigrantes y adaptación psicológica. REDES. Revista Hispana para el Análisis de Redes Sociales, (1).

Maya-Jariego, I. (2004). Sentido de comunidad y potenciación comunitaria. Apuntes de Psicología, 22 (2), 187-211.

Maya-Jariego, I. (2006). Mallas de paisanaje: el entramado de relaciones de los inmigrantes. En Pérez Pont, J. L. (Ed.). Geografías del desorden. Migración, alteridad y nueva esfera social, 257276. Universidad de Valencia: Valencia.

Maya-Jariego, I. (2016). 7 usos del análisis de redes en la intervención comunitaria. REDES. Revista Hispana para el Análisis de Redes Sociales, 27(2), 1-10.

Maya-Jariego, I. \& Holgado, D. (2015). Network analysis for social and community interventions. Psychosocial Intervention, 24(3), 121-124.

Maya-Jariego, I., \& Holgado, D. (2015b). Living in the metropolitan area. Correlation of interurban mobility with the structural cohesion of personal networks and the originative sense of community. Psychosocial Intervention, 24(3), 185-190.

Maya Jariego, I., Holgado, D., Márquez, E. \& Santolaya, F. J. (2018). The community role of schools in Jicamarca and Villa El Salvador (Peru): crosscutting behavior settings in personal networks. Psychosocial Intervention, 27 (1), 1-11. https://doi.org/10.5093/pi2018a3 
Maya-Jariego, I., Letina, S. \& González-Tinoco, E. (2018). Personal networks and psychological attributes: exploring individual differences in personality and sense of community and their relationship to the structure of personal networks. Submitted.

McCarty, C., Killworth, P. D., Bernard, R. H., Johnsen, E. C. \& Shelley, G. A. (2000). Comparing two methods for estimating network size. Human Organization, 60, 28-39.

McCarty, C. \& Molina, J. L. (2014). Social Network Analysis. In H. R. Bernard \& C. Gravlee (Eds.). Handbook of Methods in Cultural Anthropology. Lanham: Rowman \& Littlefield, pp. 631-657.

Molina, J. L. (2005). El estudio de las redes personales: contribuciones, métodos y perspectivas. EMPIRIA. Revista de Metodología de las Ciencias Sociales, 10, 71-105.

Neal, Z. P., \& Neal, J. W. (2017). Network Analysis in Community Psychology: Looking Back, Looking Forward. American Journal of Community Psychology, 60(1-2), 279-295.

Quiroz Saavedra, R., Brunson, L., \& Bigras, N. (2017). Transforming Social Regularities in a Multicomponent Community-Based Intervention: A Case Study of Professionals' Adaptability to Better Support Parents to Meet Their Children's Needs. American Journal of Community Psychology, 59, 316-332.

Roberts, S. G., Wilson, R., Fedurek, P., \& Dunbar, R. I. M. (2008). Individual differences and personal social network size and structure. Personality and Individual Differences, 44(4), 954964.

Scott, J. (2017). Social network analysis. Sage.

Selden, M., \& Goodie, A. S. (2018). Review of the effects of Five Factor Model personality traits on network structures and perceptions of structure. Social Networks, 52, 81-99.

Valente, T. W. (2012). Network interventions. Science, 337(6090), 49-53.

Wasserman, S., \& Faust, K. (1994). Social network analysis: Methods and applications. Cambridge university press: Cambridge.

Wölfer, R., Faber, N. S., \& Hewstone, M. (2015). Social network analysis in the science of groups: Cross-sectional and longitudinal applications for studying intra-and intergroup behavior. Group Dynamics: Theory, Research, and Practice, 19(1), 45-61. 


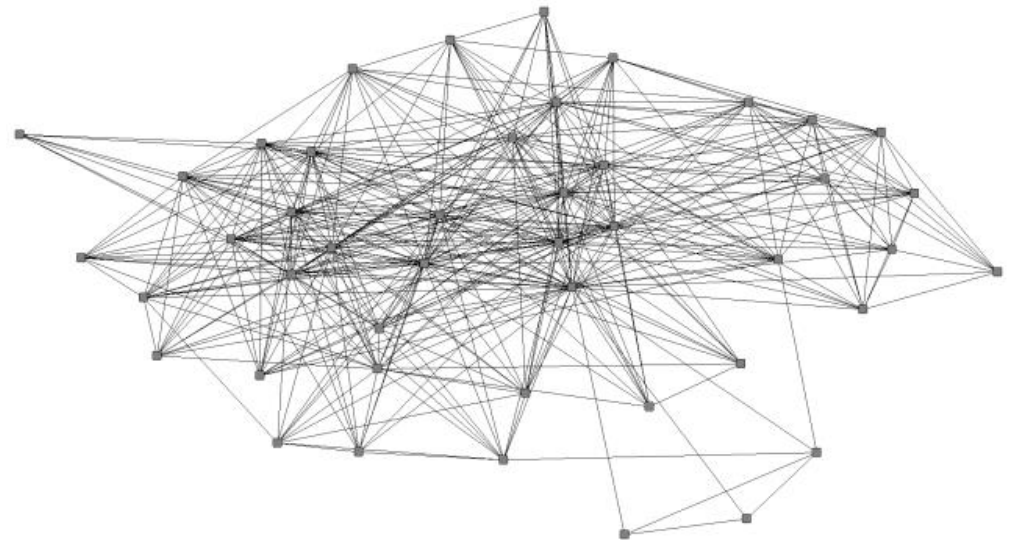

Density $=0.411 ;$ Number of cliques $=53$.

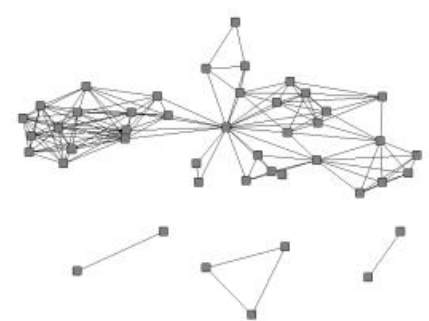

Density $=0.149 ;$ Number of cliques $=25$

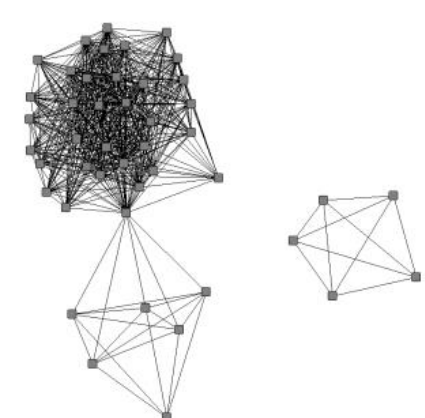

Density $=0.531 ;$ Number of cliques $=7$.

Fig. 1. Three different networks obtained with a name generator of 45 alters.

Using the same observation criteria, such as a fixed number of alters, facilitates comparison and possibly pattern detection. Given that there is normally a high multi-collinearity between the different network measures, imposing the same structure simplifies the task of interpreting the data. Some of the most effective strategies in exploratory visual analysis are precisely related in being more selective in the relationship to be examined or in the grouping criteria between actors, which usually facilitates the detection of the underlying structure. The same is true in network analysis. 